\title{
Screening and Characterization of Nitrite Degrading Lactobacillus plantarum in Chinese Traditional Pickles
}

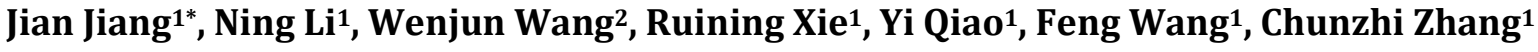 \\ ${ }^{1}$ Department of Public Health, Jining Medical University, Jining, China \\ ${ }^{2}$ Department of nursing, Jining Medical University, Jining, China \\ Email: *329968762@qq.com.cn
}

How to cite this paper: Jiang, J., Li, N., Wang, W.J., Xie, R.N., Qiao, Y., Wang, F. and Zhang, C.Z. (2021) Screening and Characterization of Nitrite Degrading Lactobacillus plantarum in Chinese Traditional Pickles. Food and Nutrition Sciences, 12, 1287-1298. https://doi.org/10.4236/fns.2021.1212094

Received: November 16, 2021

Accepted: December 21, 2021

Published: December 24, 2021

Copyright $\odot 2021$ by author(s) and Scientific Research Publishing Inc. This work is licensed under the Creative Commons Attribution International License (CC BY 4.0).

http://creativecommons.org/licenses/by/4.0/

\begin{abstract}
A Gram-positive, non-spore, round ended, straight rod Lactic acid bacteria were screened. The strain was screened out from the traditional pickle jar in Yutang soy sauce garden of Jining. In order to degrade the nitrate content in the fermentation process of traditional pickles and improve the quality of pickles, it is necessary to screen out nitrite degrading strains from pickles, and preliminarily locate nitrite reductase, and find out the most suitable $\mathrm{pH}$, temperature and culture time to degrade nitrite. Lactobacillus plantarum was screened by MRS medium in advance. After 48 hours of culture in a shaking table with Bacillus subtilis, the cell components were separated by centrifugation, wall breaking and other operations. After 20 hours at $30^{\circ} \mathrm{C}$, the content of nitrite in each component was determined by the naphthalene ethylenediamine hydrochloride method (NIR). The culture conditions were as follows: inoculation amount $3 \%, 6 \%, 9 \%, 12 \%, 15 \%$; salinity $2 \%, 4 \%, 6 \%, 8 \%, 10 \%$; temperature $15^{\circ} \mathrm{C}, 20^{\circ} \mathrm{C}, 25^{\circ} \mathrm{C}, 30^{\circ} \mathrm{C}, 35^{\circ} \mathrm{C}$ for $20 \mathrm{~h}$. The results showed that the best degradation effect of nitrite was obtained under the conditions of $9 \%$ inoculum, salinity $5 \%$ and $30^{\circ} \mathrm{C}$. Under the conditions of $9 \%$ inoculum, $5 \%$ salinity and $30^{\circ} \mathrm{C}$ for $5 \mathrm{~h}, 10 \mathrm{~h}, 20 \mathrm{~h}, 48 \mathrm{~h}, 66 \mathrm{~h}$ and $78 \mathrm{~h}$, the results showed that the degradation amount gradually increased with the extension of time, and gradually maintained a stable state. Lactobacillus plantarum JBA-3 is a new type of lactic acid bacteria which can degrade nitrite and produce nitrite reductase.
\end{abstract}

\section{Keywords}

Lactobacillus Plantarum, Soy Sauce Pickles, Nitrite Degradation

\section{Introduction}

Nitrite is a class 2A carcinogen released by the World Health Organization for 
international cancer research. Nitrite is widely found in food, especially in pickled vegetables [1]. Nitrite will be produced in the process of vegetable pickling. When the human body ingests a certain amount of nitrite, a series of health problems can be induced. At present, the production method of pickle and pickle is relatively backward, the hygiene is not up to standard, the bacterial pollution is serious, and the content of nitrite is high [2]. Nitrite content has become a "stumbling block" to the progress and development of pickle industry. Lactobacillus is one of the most common bacteria in nature, which exists in pickled vegetables [3]. Lactobacillus plantarum can degrade nitrite in pickles. It is of great significance for people's production and life to screen Lactobacillus plantarum strains with a strong ability to degrade nitrite. Jining pickle is famous for its good taste and high quality. The purpose of this study was to extract Lactobacillus plantarum with strong nitrite degradation ability from Jining pickles [4] and provide the reference for selecting suitable nitrite degrading Lactobacillus plantarum in the process of pickle production [5].

Nitrite is a potential carcinogen, which is produced in the process of vegetable fermentation, which brings potential problems to food safety. Intake of large amounts of nitrite can lead to methemoglobinemia and acute poisoning [6] [7]. Under appropriate conditions, nitrite reacts with amine, the product of protein decomposition, to form $\mathrm{N}$-nitroso compounds. At present, more than 100 kinds of $\mathrm{N}$-nitroso compounds have been synthesized, of which $80 \%$ are strong carcinogens in animals [8]. However, nitrite is also widely used in the meat industry to prevent the growth of Clostridium botulinum, and is also used as a colorant. Therefore, limiting nitrite in food is the focus of food safety research [9]. It was found that inoculating lactic acid bacteria could inhibit the accumulation of high concentration nitrite in pickle fermentation [10]. It has also been reported that more than 10 different Lactobacillus strains have been inoculated, including Lactobacillus brevis, Lactobacillus fermentans, Lactobacillus acidophilus and Lactobacillus plantarum, which can effectively reduce the concentration of nitrite during the fermentation of pickles and meat [11] [12] [13]. Our previous studies have shown that inoculation with Lactobacillus plantarum JBA-3 can significantly reduce the nitrite concentration in fermented pickles. However, little is known about the pathway and mechanism of nitrite degradation by lactic acid bacteria, the key enzymes involved in the process, and the subcellular localization of the enzyme. The effect of Lactobacillus plantarum JBA-3 on nitrite degradation during pickle fermentation and its influencing factors were studied. At the same time, the activity of NIR in different cell parts was detected to determine the subcellular localization of NIR.

\section{Methods}

\subsection{Medium}

Mrs solid medium [14] [15]: glucose $10 \mathrm{~g}$, agar $20 \mathrm{~g}$, peptone $5 \mathrm{~g}, \mathrm{KH}_{2} \mathrm{PO}_{4} 2 \mathrm{~g}$, yeast extract $2 \mathrm{G}$, calcium carbonate powder $15 \mathrm{~g}$, distilled water $1000 \mathrm{~mL}, \mathrm{pH}$ 
7.0. Liquid medium: glucose $10 \mathrm{~g}$, peptone $5 \mathrm{~g}, \mathrm{KH}_{2} \mathrm{PO}_{4} 2 \mathrm{~g}$, yeast extract $2 \mathrm{G}$, distilled water $1000 \mathrm{~mL}, \mathrm{pH} 7.0$.

\subsection{Isolation of Lactobacillus plantarum}

$1 \mathrm{~g}$ of pickle is randomly cut into a mortar, added with $1 \mathrm{~mL}$ normal saline, fully ground, and left for 15 minutes, then put into the ultra clean table. The pickle samples of Yutang soy sauce were diluted with normal saline according to the concentration gradient of $10^{-1}-10^{-3}$ : Six EP tubes were prepared, numbered 1, 2, $3,4,5$ and 6 on the tube rack, and the bacterial solution of different concentrations was prepared in EP [16]. Colony observation: under the microscope, the direct microscopic examination was carried out first. Gram staining was performed before microscopic examination. The strains with large calcium dissolving circle were selected from the plate and purified repeatedly on Mrs solid medium. Lactobacillus plantarum was screened and inoculated into liquid medium.

\subsection{Screening of Nitrite Degrading Lactobacillus plantarum}

According to the method of naphthalene ethylenediamine hydrochloride, the nitrite degradation ability of Lactobacillus plantarum was measured. The selected Lactobacillus plantarum was inoculated into Mrs liquid medium containing the appropriate amount of $\mathrm{NaNO}_{2}$, and blank control was made at the same time. The content of $\mathrm{NaNO}_{2}$ in fermentation broth was detected after 24 hours of incubation in constant temperature incubator [17].

\subsection{Physiological and Biochemical Identification of Nitrite Degrading Lactobacillus plantarum}

Lactobacillus plantarum, which was screened in 2.3, was activated for 2 generations and inoculated into Mrs agar medium. After 24 hours of culture, the morphology of the strain was observed. The physiological and biochemical characteristics of Lactobacillus plantarum were identified according to "Berger's Bacteria Identification Manual" and "plant lactobacillus classification and identification and experimental methods" [18]. The carbon source utilization test was conducted by biochemical identification tube.

\subsection{Molecular Biological Identification of Nitrite Degrading Lactobacillus plantarum}

According to the $16 \mathrm{~S}$ rDNA gene sequence, a universal primer $27 \mathrm{~F}$ was designed: 5'-agagttttgatcctggctcag-3', 1492r: 5'-cggttacttgttacgcactt-3'. The whole genome of nitrite degrading Lactobacillus plantarum was extracted and amplified by $16 \mathrm{~S}$ rRNA bacteria with primers. The amplification system was $25 \mathrm{ul}$ PCR reaction system. The amplification reaction conditions were as follows: pre denaturation at $94^{\circ} \mathrm{C}$ for $3 \mathrm{~min}$, denaturation at $94^{\circ} \mathrm{C}$ for $30 \mathrm{~s}$, annealing at $52^{\circ} \mathrm{C}$ for $1.5 \mathrm{~min}$, extending for $2 \mathrm{~min}$ and $30 \mathrm{~s}$ at $72^{\circ} \mathrm{C}$ for 35 cycles and extending for $10 \mathrm{~min}$ at $72^{\circ} \mathrm{C}$. Blast was used for homology comparison. PCR products were sent to Shenggong Bioengineering (Shanghai) Co., Ltd. for sequencing. The sequence 
was compared by blast in GenBank and identified to species [19].

\subsection{Phylogenetic Tree}

The PCR product was purified and sequenced as described previously [20]. BLAST analysis for $16 \mathrm{~S}$ rRNA gene sequences was done on National Center for Biotechnology Information (NCBI) database. The sequence was multiply aligned with the selected sequences of type strains obtained from GenBank/EMBL/DDBJ databases by using Clustal W version 1.81. A phylogenetic tree was reconstructed using MEGA5.0 software, based on the neighbour-joining, maximum-parsimony and maximum likelihood methods.

\subsection{Parameter Optimization by Response Surface Methodology}

In this study, RSM was used to identify the effects of optimum parameters of four variables, Inoculation quantity (A), salinity (B), temperature (C), and $\mathrm{Ni}$ trite degradation rate $(\mathrm{D})$, on the yield of Nitrite degradation. To estimate the model coefficients, a three-factor-three-level Box Benhnken experiment was performed (29 runs), and the order of the experiments was randomized, analysis of the experimental design data and the calculation of the predicted responses were computed by using SPSS Statistics 22.0. Additional confirmatory experiments were subsequently conducted to verify the reliability of the statistical experimental design [21].

\subsection{Pickle Fermentation}

Lactobacillus plantarum JBA-3 was inoculated into sterilized MRS medium and incubated at $30^{\circ} \mathrm{C}$ for 24 hours without shaking to produce seed solution. Then, $5 \%$ of the seed liquid was added to the liquid MRS medium to bring the bacteria to $10^{7}-10^{8} \mathrm{CFU} / \mathrm{mL}$, and then incubated at $30^{\circ} \mathrm{C}$ for 24 hours without shaking to produce a secondary seed solution [22]. The fermentation process of pickles is carried out according to the following procedures: fresh cucumber cleaning, drying, segmentation, blanching. Add 5\% secondary seed liquid and soy sauce. Fermentation was carried out at $37^{\circ} \mathrm{C}$ in sealed bottles for 120 hours. Samples of fermented pickles were collected regularly under aseptic conditions to detect the concentration of nitrite [23]. Fermentation is also carried out under sterile conditions. In order to obtain the best growth and anaerobic fermentation of lactic acid bacteria, pickles were not exposed to the air in a large number of secondary seed liquid. The control group $\left(\mathrm{CK}_{0}\right)$ was fermented with conventional pickles and was not inoculated with Lactobacillus plantarum JBA-3.

\section{Results}

\subsection{Isolation of Lactobacillus Plantarum}

The supernatant of ground pickle was extracted and prepared into different concentrations of bacterial solution in EP tube. The higher the dilution concentration was, the higher the number of colonies was detected (Table 1). Morphological 
Table 1. Number of colonies corresponding to different dilution.

\begin{tabular}{ccccc}
\hline Dilution & $10^{-4}$ & $10^{-5}$ & $10^{-6}$ & $10^{-7}$ \\
\hline CFU & ND & 421 & 69 & 21 \\
\hline
\end{tabular}

ND: Not Detected.

observation was carried out to observe the morphology of the better growing colonies. After Gram staining, Lactobacillus plantarum was dyed blue purple, which proved that Lactobacillus plantarum was Gram-positive (Figure 1). The strains with large calcium dissolving circle were selected from the plate and purified repeatedly on Mrs solid medium. Finally, the Lactobacillus plantarum JBA-3 strains with the largest calcium dissolving circle were selected. More than 300 strains were isolated, and one strain with high nitrite degradation activity was found, and inoculated into liquid medium to screen Lactobacillus plantarum.

\subsection{Phylogenetic Tree}

Neighbour-joining tree based on an almost complete 16S rRNA gene sequence (1492 nt) showing the relationships among strain Lactobacillus plantarum JBA-3 and related type strains (Figure 2). Phylogenetic tree was constructed by using related strains of Lactobacillus. Asterisks $\left(^{*}\right)$ and hashes (\#) indicate that the corresponding nodes were also found in trees generated with the maximumlikelihood and maximum-parsimony algorithms, respectively. The numbers at branch nodes indicate bootstrap percentages derived from 1000 replications; only values $>50 \%$ are shown. Bar, 0.01 substitutions per single nucleotide position.

\subsection{Response Surface Analysis}

The response surface 3D map (Figure 3 ) showed the combined effects of different factors on the response (Nitrite degradation rate). The experimental data were fitted to equation, with the following optimal operating parameters: (a): Inoculation quantity, 9.13\%; (b): salinity, 5.41\%; (c): temperature, $30.19^{\circ} \mathrm{C}$; (d): Nitrite degradation rate, $91.47 \%$.

\subsection{Dynamic Change of Nitrite Concentration in Pickle Fermentation}

The nitrite concentration of fermented pickles after different fermentation time is shown in Figure 4. The content of nitrite in fermented pickles without Lactobacillus plantarum JBA-3 $18.35 \mathrm{mg} / \mathrm{Kg}$ and $51.26 \mathrm{mg} / \mathrm{Kg}$, which decreased to $1.75 \mathrm{mg} / \mathrm{Kg}$ and $0.89 \mathrm{mg} / \mathrm{Kg}$ after $24 \mathrm{~h}$ and $48 \mathrm{~h}$ fermentation by Lactobacillus plantarum JBA-3. The content of nitrite after 72 hours of fermentation is higher than that of after 48 hours from Figure 4. Compared with the conventional fermentation, the nitrite concentration in the fermentation system with Lactobacillus plantarum JBA-3 was significantly lower $(\mathrm{P}<0.01)$. The nitrite concentration 


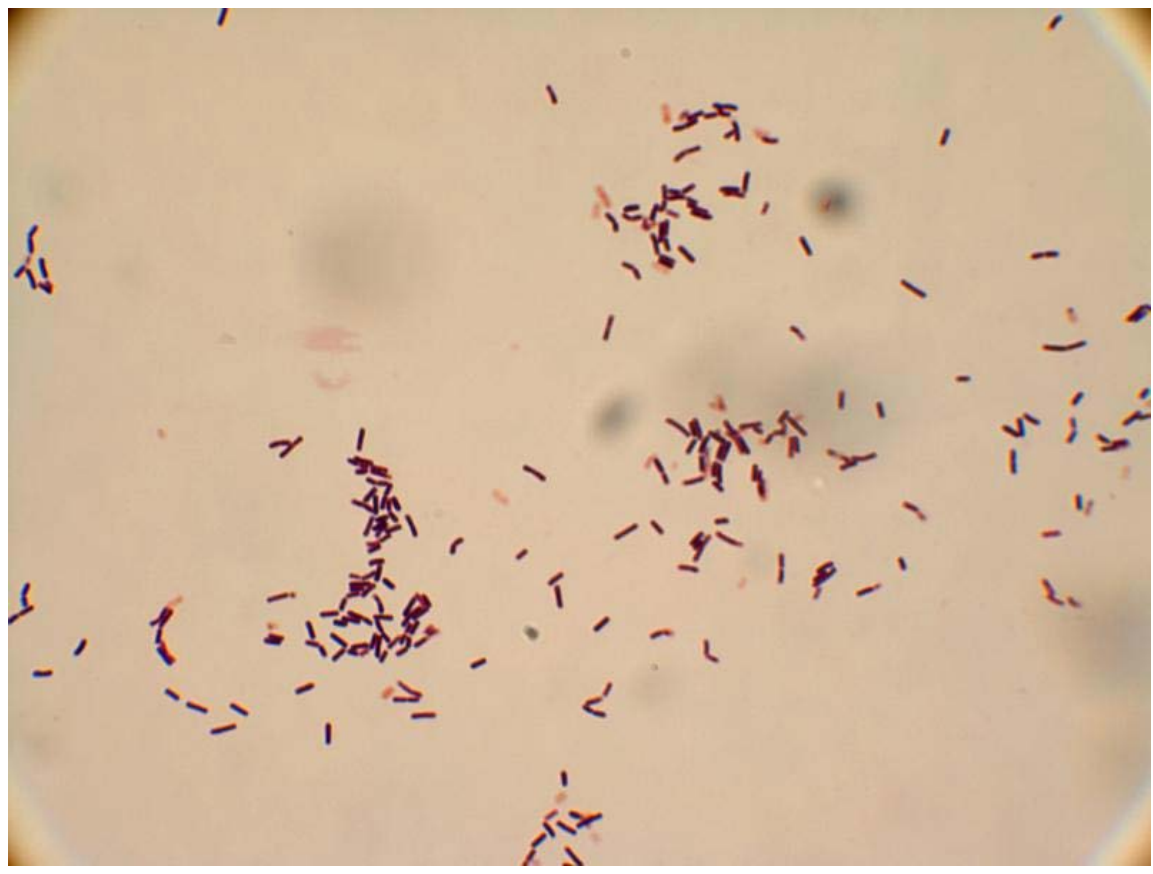

Figure 1. General optical micrograph of cells of strain Lactobacillus plantarum JBA-3 grown in Mrs broth at $30^{\circ} \mathrm{C}$ for $24 \mathrm{~h}(400 \times)$. Morphological observation was carried out to observe the morphology of the better growing colonies. After Gram staining, Lactobacillus plantarum was dyed blue purple, which proved that Lactobacillus plantarum was Gram-positive.

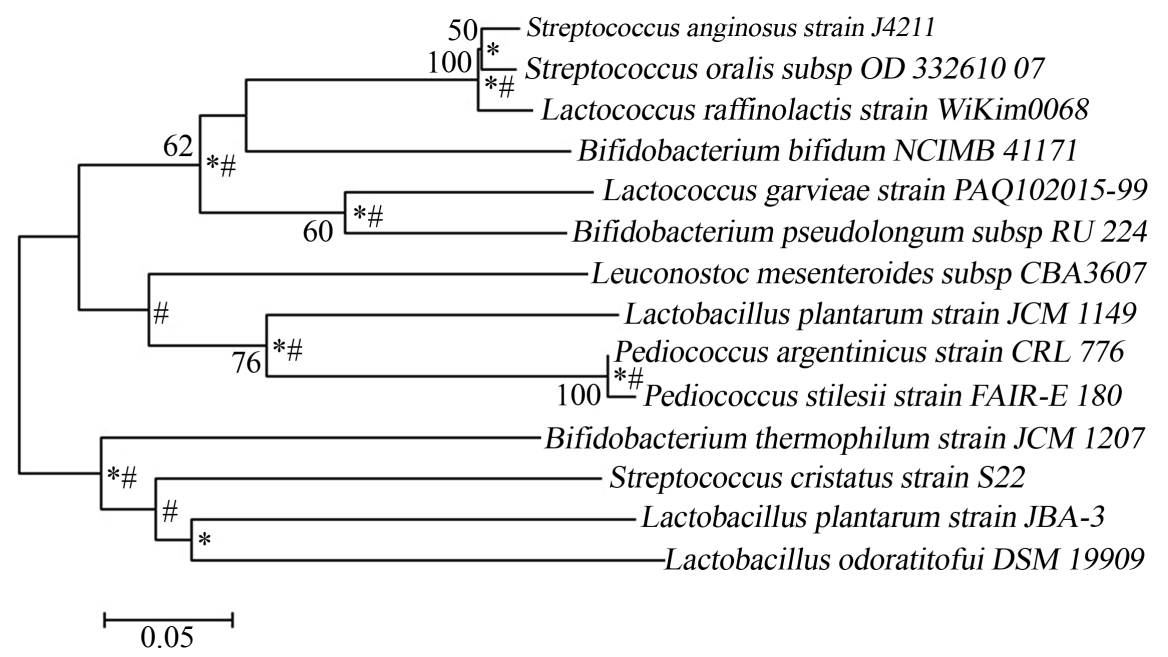

Figure 2. Neighbour-joining tree based on an almost complete 16S rRNA gene sequence (1492 nt) showing the relationships among strain Lactobacillus plantarum JBA-3 and related type strains. Asterisks $\left(^{*}\right)$ and hashes $(\#)$ indicate that the corresponding nodes were also found in trees generated with the maximum-likelihood and maximum-parsimony algorithms, respectively.

in fermented pickles without Lactobacillus plantarum JBA-3 increased first and then decreased, and the highest concentration reached $51.26 \mathrm{mg} / \mathrm{Kg}$ after $48 \mathrm{~h}$ fermentation, which was consistent with the previous report. Therefore, Lactobacillus plantarum JBA-3 could significantly inhibit the abnormal accumulation 
Design-Expert?Software

Factor Coding: Acual

Ntite degradation rate (\%)

- Design points above predicted value

- Design points below predicted value

$\left[\begin{array}{l}92 \\ 50\end{array}\right.$

$\mathrm{X} 1=(\mathrm{a})$ : Inoculation quantity $\mathrm{X} 2$ = (b): salinity

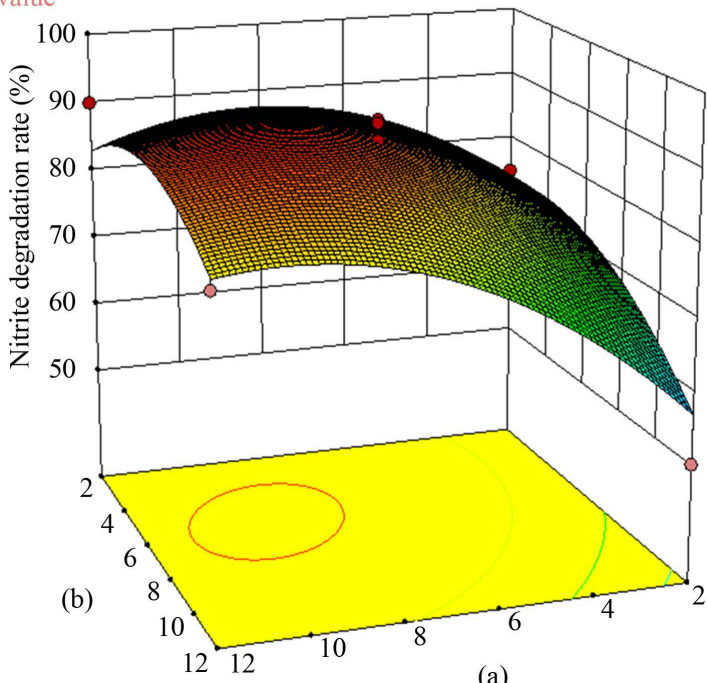

(a)

Figure 3. The 3D response surface of nitrite degradation rate affected by Inoculation quantity, salinity, and temperature. Inoculation quantity (\%) (a), salinity (\%) (b), temperature, nitrite degradation rate, on the yield of Nitrite degradation. To estimate the model coefficients, a three-factor-three-level Box Benhnken experiment was performed (29 runs).

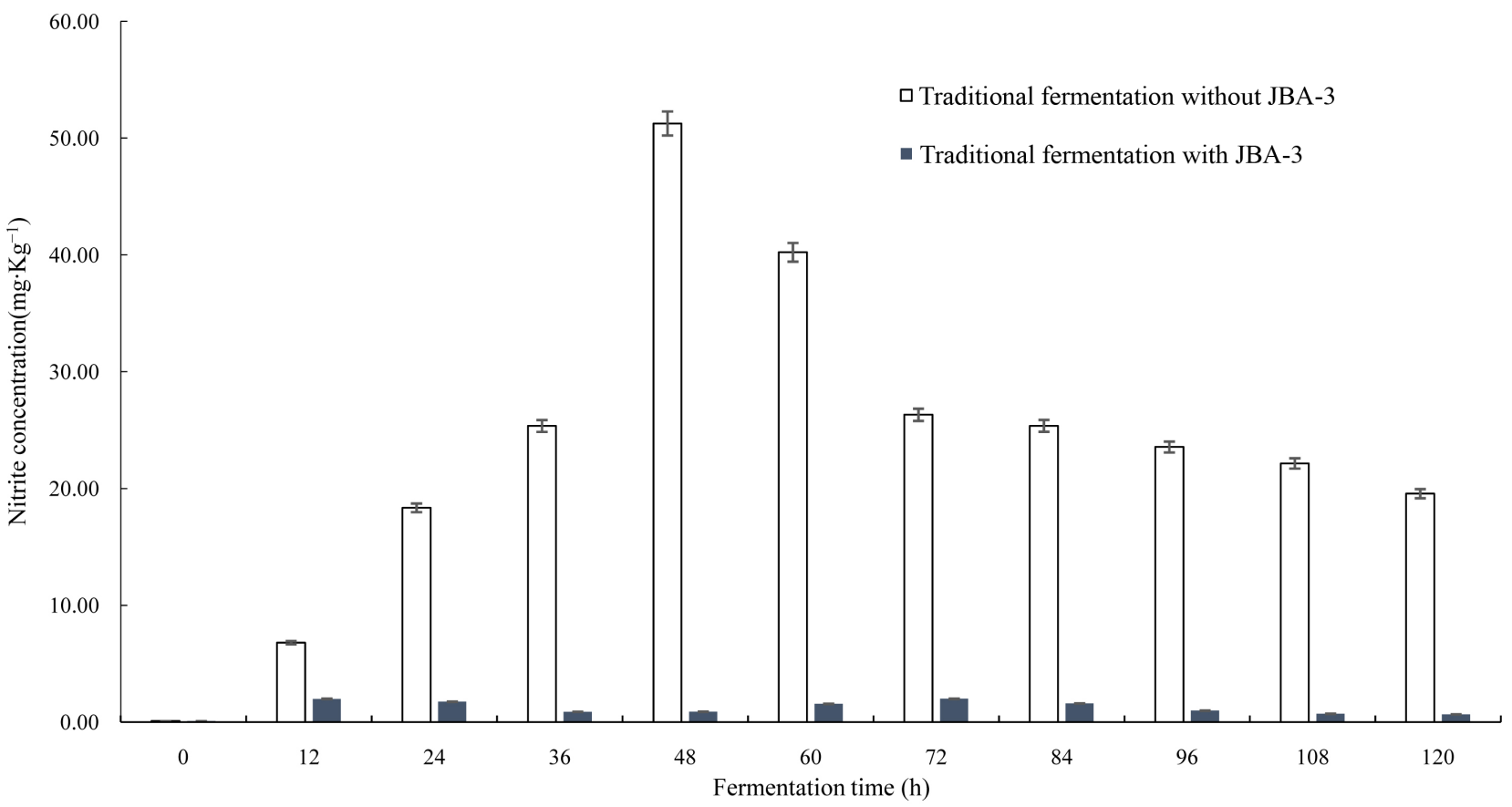

Figure 4. Nitrite concentration during the fermentation of traditional pickles with and without Lactobacillus plantarum JBA-3.

of nitrite during the fermentation of pickles. For a long time, high concentration of nitrite in food has been a research hotspot in the field of food safety. The potential reason of nitrite accumulation in Chinese pickles was studied. The results 
showed that nitrate accumulated in the process of bacterial fermentation, and lactic acid fermentation reduced nitrate concentration. High concentration of nitrite was maintained for a long time. The abnormal accumulation of nitrite in pickles was related to the following factors: 1) The number of coliforms was higher than that of the control group; 2) The concentration of soluble nitrogen compounds was higher than that of the control group; 3 ) The buffering capacity of the control group was higher than that of the control group. These results suggest that the abnormal accumulation is caused by the long-term survival of coliforms that promote nitrate reduction. Lactobacillus delbrueckiicidca 133 inhibited the nitrate reductase activity of Escherichia coli. The nitrate reductase activity was closely related to the number of viable cells of Lactobacillus, rather than low $\mathrm{pH}$ value. This indicates that some substances are directly transferred from Lactobacillus to Escherichia colis.

\section{Discussion}

The most suitable $\mathrm{pH}$ value of lactic acid bacteria was obtained from this experiment. According to the method of naphthalene ethylenediamine hydrochloride in China National Quality Standard (GB/T 5009.33-2003 determination of nitrite and nitrate in food), Lactobacillus plantarum JBA-3 with strong nitrite degradation ability was selected. Lactobacillus plantarum JBA-3 was extracted from pickles in Jining area. It was proved that the nitrite content in the pickles produced by the lactic acid bacteria may be low and the harm to human body is low. The selected Lactobacillus plantarum JBA-3 can improve the taste and flavor of pickles, reduce the content of nitrite, reduce the pickling time and improve the economic benefits. Lactobacillus plantarum JBA-3 can also be used to produce other aspects of life, such as the production of yogurt, medicine and so on.

Lactobacillus plantarum JBA-3 is active in the temperature range of $15-40$, can degrade sodium nitrite, has the ability to decompose D-glucose and malic acid, and can secrete amylase, arginase and urease (Table 2). The degradation amount of nitrite in Periplasmic NiR was $1.15 \mathrm{mg} / \mathrm{L}$ and the enzyme activity was 15.5 U. The degradation of nitrite in Cytoplasmic NiR was $98.66 \mathrm{mg} / \mathrm{L}$ and the enzyme activity was $1327.6 \mathrm{U}$ (Table 3 ). The enzyme activity of periplasmic NIR was determined by culturing bacteria at $30^{\circ} \mathrm{C}$ for $20 \mathrm{~h}$, and then the culture medium was centrifuged at $8000 \mathrm{rpm}$ for $20 \mathrm{~min}$. The supernatant was taken for enzyme activity determination.

The method for determining the enzyme activity of nitrosamic NIR was as follows: firstly, the bacteria were cultured at $30^{\circ} \mathrm{C}$ for $20 \mathrm{~h}$, the culture medium was centrifuged at $8000 \mathrm{rpm}$ for $20 \mathrm{~min}$, and then the precipitate was diluted and put into two $2 \mathrm{ml}$ EP tubes respectively. After crushing for $20 \mathrm{~min}$, the crushing solution was centrifuged at 10,000 rpm for $20 \mathrm{~min}$. Finally, the supernatant was taken to determine the enzyme activity of nitrite reductase.

Lactobacillus plantarum JBA-3, which can degrade nitrite, is not the dominant strain in the traditional process of pickle fermentation. In the traditional 
Table 2. Differential characteristics of strain JBA-3 Andrelated species of the lactobacillus.

\begin{tabular}{|c|c|c|c|}
\hline Characteristic & $\begin{array}{c}\text { Lactobacillus } \\
\text { plantarum } \\
\text { JBA-3 }\end{array}$ & $\begin{array}{c}\text { Lactobacillus } \\
\text { brevis } \\
\text { ATCC } 367\end{array}$ & $\begin{array}{c}\text { Pediococcus } \\
\text { cerevisiae } \\
\text { NCIMB12174 }\end{array}$ \\
\hline Temperature for growth $\left({ }^{\circ} \mathrm{C}\right)$ & $15-40$ & $10-42$ & $4-37$ \\
\hline $\mathrm{pH}$ for growth & $5-8$ & $5.5-9$ & $5.5-8$ \\
\hline Nitrate reduction & + & - & - \\
\hline Gelatin hydrolysis & - & + & - \\
\hline PET hydrolysis & - & - & + \\
\hline \multicolumn{4}{|l|}{ Assimilation of: } \\
\hline L-Arabinose & - & + & - \\
\hline D-Glucose & + & - & + \\
\hline Capric acid & - & - & + \\
\hline Malic acid & + & + & + \\
\hline Trisodium citrate & - & + & - \\
\hline D-Mannitol & - & - & + \\
\hline \multicolumn{4}{|l|}{ Enzyme activities: } \\
\hline amylase & + & + & - \\
\hline hippuricase & - & + & - \\
\hline Arginase & + & + & + \\
\hline urease & + & + & - \\
\hline Isolation source & Soy sauce pickles & Cheese & Fermented food \\
\hline
\end{tabular}

Strains: 1, Lactobacillus plantarum JBA-3; 2, Lactobacillus brevisATCC367; 3, Pediococcus cerevisiaeNCIMB12174. All phenotypic characteristics were determined in this study. +: Positive; -: Negative.

Table 3. The location of nitrite reductase in JBA-3.

\begin{tabular}{cccc}
\hline & Periplasmic NiR & Cytoplasmic NiR & CK \\
\hline $\mathrm{NaNO}_{2}$ degradation $(\mathrm{mg} / \mathrm{L})$ & 1.15 & 15.5 & 0.0012 \\
Enzyme activity $(\mathrm{U})$ & 98.66 & 1327.6 & - \\
\hline
\end{tabular}

Data were presented as the mean standard deviation (S.D.). The degradation amount of nitrite in Periplasmic NiR was $1.15 \mathrm{mg} / \mathrm{L}$ and the enzyme activity was $15.5 \mathrm{U}$. The degradation of nitrite in Cytoplasmic NiR was $98.66 \mathrm{mg} / \mathrm{L}$ and the enzyme activity was 1327.6 U.

fermentation of pickles, Lactobacillus plantarum JBA-3 was not enriched to control the accumulation of nitrite in pickles. In our improved production process, we can increase the number of Lactobacillus plantarum JBA-3 ahead of time. In the process of pickle fermentation, we can establish the fermentation production 
system of Lactobacillus plantarum JBA-3 which can degrade nitrite as the dominant strain. In the whole process of pickle production, the synthesis and accumulation of nitrite can be controlled to make the pickle safer.

\section{Acknowledgements}

We thank Ning Li, Wenjun Wang, Ruining Xie, Chunzhi Zhang, $\mathrm{Na} \mathrm{Li,} \mathrm{Lun}$ Wang and Jiaozhuo Li for technical assistance and helpful discussions.

\section{Authors' Contributions}

J. J., N. L., W. J. W., R. N. X. performed experiments. Y. Q. and C. Z. Z. analysed data. F. W. provided project administration and funding. J. J. and N. L. wrote the manuscript.

\section{Conflicts of Interest}

The authors declare that there are no conflicts of interest.

\section{Funding Information}

This work was supported by Shandong Provincial Natural Science Foundation of China [ZR2017BC083], NSFC cultivation project of Jining Medical University [JYP201721], Research Support Foundation of Jining Medical University [JYFC2018KJ001].

\section{References}

[1] Wang, X.H., Ren, H.Y., Liu, D.Y., et al. (2013) Effects of Inoculating Lactobacillus sakei Starter Cultures on the Microbiological Quality and Nitrite Depletion of Chinese Fermented Sausages. Food Control, 32, 591-596.

https://doi.org/10.1016/j.foodcont.2013.01.050

[2] White, J.W. (1975) Relative Significance of Dietary Sources of Nitrate and Nitrite. Journal of Agricultural and Food Chemistry, 23, 886-891.

[3] Chan, T.Y.K. (2011) Vegetable-Borne Nitrate and Nitrite and the Risk of Methaemoglobinaemia. Toxicology Letters, 200, 107-108.

https://doi.org/10.1016/j.toxlet.2010.11.002

[4] Chen, Y., Bai, Y., Li, D.S., et al. (2016) Screening and Characterization of EthanolTolerant and Thermotolerant Acetic acid Bacteria from Chinese Vinegar Pei. World Journal of Microbiology \& Biotechnology, 32, Article No. 14. https://doi.org/10.1007/s11274-015-1961-8

[5] Andreoni, V., Luischi, M.M., Cavalca, L., et al. (2000) Selenite Tolerance and Accumulation in the Lactobacillus Species. Annals of Microbiology, 50, 77-88.

[6] Spencer, J.P.E., Whiteman, M., Jenner, A., et al. (2000) Nitrite-Induced Deamination and Hypochlorite-Induced Oxidation of DNA in Intact Human Respiratory Tract Epithelial Cells. Free Radical Biology \& Medicine, 28, 1039-1050. https://doi.org/10.1016/S0891-5849(00)00190-8

[7] Santamaria, P. (2006) Nitrate in Vegetables: Toxicity, Content, Intake and EC Regulation. Journal of the Science of Food and Agriculture, 86, 10-17. https://doi.org/10.1002/jsfa.2351 
[8] Sen, N.P., Seaman, S.W., Baddoo, P.A., et al. (2001) Formation of N-Nitroso$N$-Methylurea in Various Samples of Smoked/Dried Fish, Fish Sauce, Seafoods, and Ethnic Fermented/Pickled Vegetables Following Incubation with Nitrite under Acidic Conditions. Journal of Agricultural \& Food Chemistry, 49, 2096-2103. https://doi.org/10.1021/jf0011384

[9] Hashimoto, T. (2001) The Cause on the Abnormal Accumulation of Nitrite in Pickles of Chinese Cabbage (Brassica pekinesis Rupr.). Nippon Shokuhin Kagaku Kogaku Kaishi, 48, 409-415.

[10] Çon, A.H. and Gökalp, H.Y. (2000) Production of Bacteriocin-Like Metabolites by Lactic Acid Cultures Isolated from Sucuk Samples. Meat Science, 55, 89-96.

[11] Cui, Y.H., Qu, X.J., Li, H.M., et al. (2012) Isolation of Halophilic Lactic Acid Bacteria from Traditional Chinese Fermented Soybean Paste and Assessment of the Isolates for Industrial Potential. European Food Research \& Technology, 234, 797-806. https://doi.org/10.1007/s00217-012-1689-8

[12] Buckenhüskes, H.J. (1993) Selection Criteria for Lactic Acid Bacteria to Be Used as Starter Cultures for Various Food Commodities. FEMS Microbiology Reviews, 12, 253-271.

[13] Vasiee, A.R., Yazdi, F.T., Mortazavi, A., et al. (2014) Isolation, Identification and Characterization of Probiotic Lactobacilli spp. from Tarkhineh. International Food Research Journal, 21, 2487-2492.

[14] Ángel González, Mas A. (2011) Differentiation of Acetic Acid Bacteria Based on Sequence Analysis of 16S-23S rRNA Gene Internal Transcribed Spacer Sequences. International Journal of Food Microbiology, 147, 217-222. https://doi.org/10.1016/j.ijfoodmicro.2011.04.005

[15] Huang, X.Y., Fu, H.L., Tang, H.Q., et al. (2020) Optimization Extraction of Shikonin Using Ultrasound-Assisted Response Surface Methodology and Antibacterial Studies. Evidence-Based Complementary and Alternative Medicine, 2020, Article ID: 1208617. https://doi.org/10.1155/2020/1208617

[16] Tamura, K., Peterson, D., Peterson, N., Stecher, G., Nei, M. and Kumar, S. (2011) MEGA5: Molecular Evolutionary Genetics Analysis Using Maximum Likelihood, Evolutionary Distance, and Maximum Parsimony Methods. Molecular Biology and Evolution, 28, 2731-2739. https://doi.org/10.1093/molbev/msr121

[17] Liu, D.M., Wang, P., Zhang, X.Y., et al. (2014) Characterization of Nitrite Degradation by Lactobacillus casei subsp. rhamnosus LCR 6013. PLoS ONE, 9, e93308. https://doi.org/10.1371/journal.pone.0093308

[18] Hugo, A.A., Antoni, G.L.D. and Pérez, P.F. (2006) Lactobacillus delbrueckii subsp lactis Strain CIDCA 133 Inhibits Nitrate Reductase Activity of Escherichia coli. International Journal of Food Microbiology, 111, 191-196.

https://doi.org/10.1016/j.ijfoodmicro.2006.04.024

[19] Poock, S.R., Leach, E.R., Moir, J.W.B., et al. (2002) Respiratory Detoxification of Nitric Oxide by the Cytochromec Nitrite Reductase of Escherichia coli. Journal of Biological Chemistry, 277, 23664-23669. https://doi.org/10.1074/jbc.M200731200

[20] Paik, H.D. and Lee, J.Y. (2014) Investigation of Reduction and Tolerance Capability of Lactic Acid Bacteria Isolated from Kimchi against Nitrate and Nitrite in Fermented Sausage Condition. Meat Science, 97, 609-614.

https://doi.org/10.1016/j.meatsci.2014.03.013

[21] Jiang, J., Gao, L., Bie, X., et al. (2016) Identification of Novel Surfactin Derivatives from NRPS Modification of Bacillus subtilis and Its Antifungal Activity against $\mathrm{Fu}$ sarium moniliforme. BMC Microbiology, 16, Article No. 31. 
https://doi.org/10.1186/s12866-016-0645-3

[22] Yan, P.M., Xue, W.T., Tan, S.S., et al. (2008) Effect of Inoculating Lactic Acid Bacteria Starter Cultures on the Nitrite Concentration of Fermenting Chinese Paocai. Food Control, 19, 50-55. https://doi.org/10.1016/j.foodcont.2007.02.008

[23] Samelis, J., Maurogenakis, F. and Metaxopoulos, J. (1994) Characterisation of Lactic Acid Bacteria Isolated from Naturally Fermented Greek Dry Salami. International Journal of Food Microbiology, 23, 179-196.

https://doi.org/10.1016/0168-1605(94)90051-5 